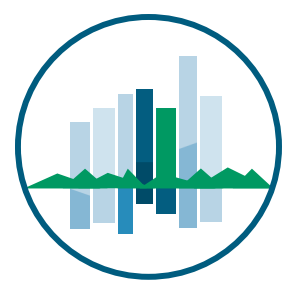

True Smart and Green City?

8th Conference of the

International Forum on Urbanism
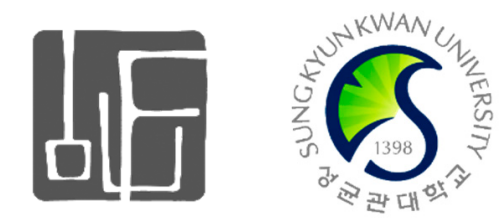

Conference Proceedings Paper

\title{
Urban Resilience: Principles for the Water Sensitive City
}

\author{
Jihye Lee
}

National University of Singapore, Centre for Sustainable Asian Cities, School of Design \&

Environment, SDE1 \#04-24, 4 Architecture Drive, Singapore 117566; Tel.: +65-9723-4523;

Fax:+65-6777-3953E-Mail: Jihye.lee06@gmail.com

\begin{abstract}
Due to the widespread recognition of climate change, urban communities are increasingly seeking to ensure not only resilience of urban water supplies in the future, but also optimising use of urban water in their community to create hydro-social benefits, which enhance the health of the urban living environment. Over 20 years, many efforts have been put into emerging research, establishing government policies, and application to the practices of transforming from the conventional water management system into the integrative sustainable water management system. However, a hydro-technical resilience system has not been established yet nor is there a common vision for doing so either internationally and locally. As many cities faced ongoing investment in the conventional system, it requires an overhaul of the existing urban water management system to move to the next stage, an adaptation process of the new approach of contextual hydro-technical systems. This paper provides an overview of the emerging research and practice, focused on principles for water sensitive city toward urban resilience especially in the context of the high-density environment, Singapore. The three key components that underpin the principles of water sensitive city are proposed; 1) socio-political system towards water sensitive community; 2) integrated socio-technical system comprising centralized and decentralized models; 3) environmental resilience in built and natural environment. While progressing towards transformation to achieve resilience, the approach of Singapore as a leading water sensitive city will be presented.
\end{abstract}

Keywords: water sensitive urban design, urban resilience, sustainable urban water management 


\section{Introduction}

Based on the rapid urbanisation of increasing population, the city has developed and expanded dramatically in the past decades. Urban development to support the demand from the society such as housing and infrastructure supplies results in a consequential impact on land and water environments. In addition, to mitigate the impacts of global warming and climate change, as well as shortage of land are the big challenges in urban life, especially in regard to sustainable water management of water resources and environmental protection. Until recently, engineering approach served urban water needs of society, however it is characterised by an engineering 'command - and control' approach, which aims to reduce current and future uncertainties through emphasising technical solutions, ignores radical alternatives and bases decision on rational cost-benefit assessments that consider a narrow set of values (Dominguez, Truffer, \& Gujer, 2011; Pahl-Wostl, 2007; Truffer, Störmer, Maurer, \& Ruef, 2010 ; Ferguson, Frantzeskaki, Brown, 2013). The pursuit of sustainability became more important in recent decades, and it aimed to protect the environment, conserve natural resources and promote the lifestyle and public health.

A critical challenge to the urban community is its design for resilience against the impact of climate change (e.g. flooding, drought and rapidly increasing annual rainfall) and population growth particularly in regards to sustainable management of urban water and protection of water resources. Several scholars stated that the conventional urban water management approach is not suitable to address current and future sustainability issues (Butler and Maksimovic, 1999; Newman, 2001; Ashley et al., 2003). It is mainly due to insufficient institutional framework and traditional compartmentalization of sewage, storm water services and water supply physical infrastructure. The conventional water management infrastructure, institutional framework and environmental resilience in built and natural environment as well as social behaviors are critical and required to overhaul current status in order to resolve the current and future challenges for resilience regarding uncertainties of water supply and urban water management issues from the impact of climate change and population growth. These water management infrastructure, institutionalisation and sustainable social behavior are key issues that help to establish long-term resilience of built and natural environment to promote livability in the urban community through urban design.

Emerging from the field of ecology in the 1970's 'Resilience' was understood as the capacity of a system or agent to maintain or recover functionality in the event of disruption or disturbance. Dalziell \& McManus (2004) further recognise resilience as "the overarching goal of a system to continue to function to the fullest possible extent in the face of stress to achieve its purpose, where resilience is a function of both the vulnerability of the system and its adaptive capacity." While focusing on a system's process of returning to an equilibrium state, following disturbance (Davoudi, 2012), 'ecological resilience' (Holling, 1973) recognise that a return to equilibrium should not automatically mean a return to a previous state. Instead, ecological resilience proposes that in restoring functionality within a system, a new equilibrium can be established, which in turn renders the system better able to manage disruption in the future. Folke (2006) terms this 'socio-ecological resilience' while Davoudi (2012) calls this third conceptualisation 'evolutionary resilience'. Such views of resilience as a transformative process accept uncertainty and change as a behavioural feature of systems and environments, rather than promoting the prediction and prevention of hazard event. The concept of 'evolutionary resilience' recognises the 
complexity of resilience in the system, as well as their continual adaptation. As Davoudi(2012) states "evolutionary resilience promote the understanding of place not as units of analysis or neutral containers, but as complex, interconnected socio-spatial systems with extensive and unpredictable feedback processes that operate at multiple scale and timeframes". In addition, Folke (2006) highlighted that resilience is not only about being persistent or robust to disturbance, it also reflects how that system creates opportunity from the disturbance for renewal and the pursuit of new trajectories. However, there are challenges of resilience: 1) concept of resilience is hard to implement and measure (Willinson, 2012); 2) it fails to describe adequately and examine social dynamics within system (Béné et al, 2012 ; Levine et al, 2012); 3) Resilience plays out at multiple scales and through a series of interdependent systems (Arup, 2014). Unlike ecological resilience, urban resilience systems are built based on the decisions made by city stakeholders and it tends to be driven by very particular motivation and human needs as well as unique structure of authority within particular cities (da Silva et al, 2012). Also, as city is built with various and complex layers of infrastructure network, while strengthening resilience particularly in urban water management in the different scales - precinct, district and city, it may have too many unintended effects. To achieve the urban resilience requires the integrative water management systems and urban design where the sustainable behavior and socio-technical system can benefit to livability in the city life.

Transforming cities to water sensitive city will require a major socio-technical overhaul of conventional approaches. Water Sensitive Urban Design (WSUD) (Wong, 2006a, 2006b) is one of building blocks to pursue urban resilience to the impact of climate change and transition process toward water sensitive city that evolved recent decades. WSUD and integration of urban water management bring hydro-socio benefits to the living environment and natural environment by providing secured water services, minimising the impact on the natural environment, maximising their contribution to social and economic vitality, therefore it engenders overall community improvement under various disciplines (Mitchell, 2006). While Singapore government is yet to provide a definition for the envisaged water sensitive city, several scholars across different disciplines strongly suggest that a water sensitive city aims to ensure supply security, public health, socioeconomic sustainability and protection and repair of the environment through water sensitive urban design; enlightened social and institutional system, and diverse and sustainable technology choices (Brown et al, 2007).

The figure 1. Urban water management transitions framework (Brown et al., 2009) indicate that the hydro-social system in a water sensitive city is adaptive as part of transition process to more sustainable water management of the city underpinned by a flexible institutional regime, and co-existing and diverse infrastructure within built and natural environment. Therefore, it reflects a detail and engaged community support of a sustainable lifestyle and would extend to the professional and practitioners in the water sector in relation to capacity of innovative and sustainable management of the urban water resources. In addition, it applies to the urban development and landscape sector as well to reinforce flexibility and diversity among urban form, infrastructure and supportive institutional context to link and create synergy between society and technology to enhance liveability. 


\section{Principles for Water Sensitive City}

This paper proposes the principles of water sensitive city translated from theory and current sociotechnical development. It helps to envisage a vision of urban resilience from the impact of climate change and synergy with the current asset of water supply and management system, which recognised as mostly centralised water management system. The three key aspects are: 1) socio-political system towards water sensitive community; 2) integrated socio-technical system comprising centralized and decentralized models; 3 ) environmental resilience in built and natural environment.

Figure 1. Urban water Management Transitions Framework (Source: Brown et al. 2009).

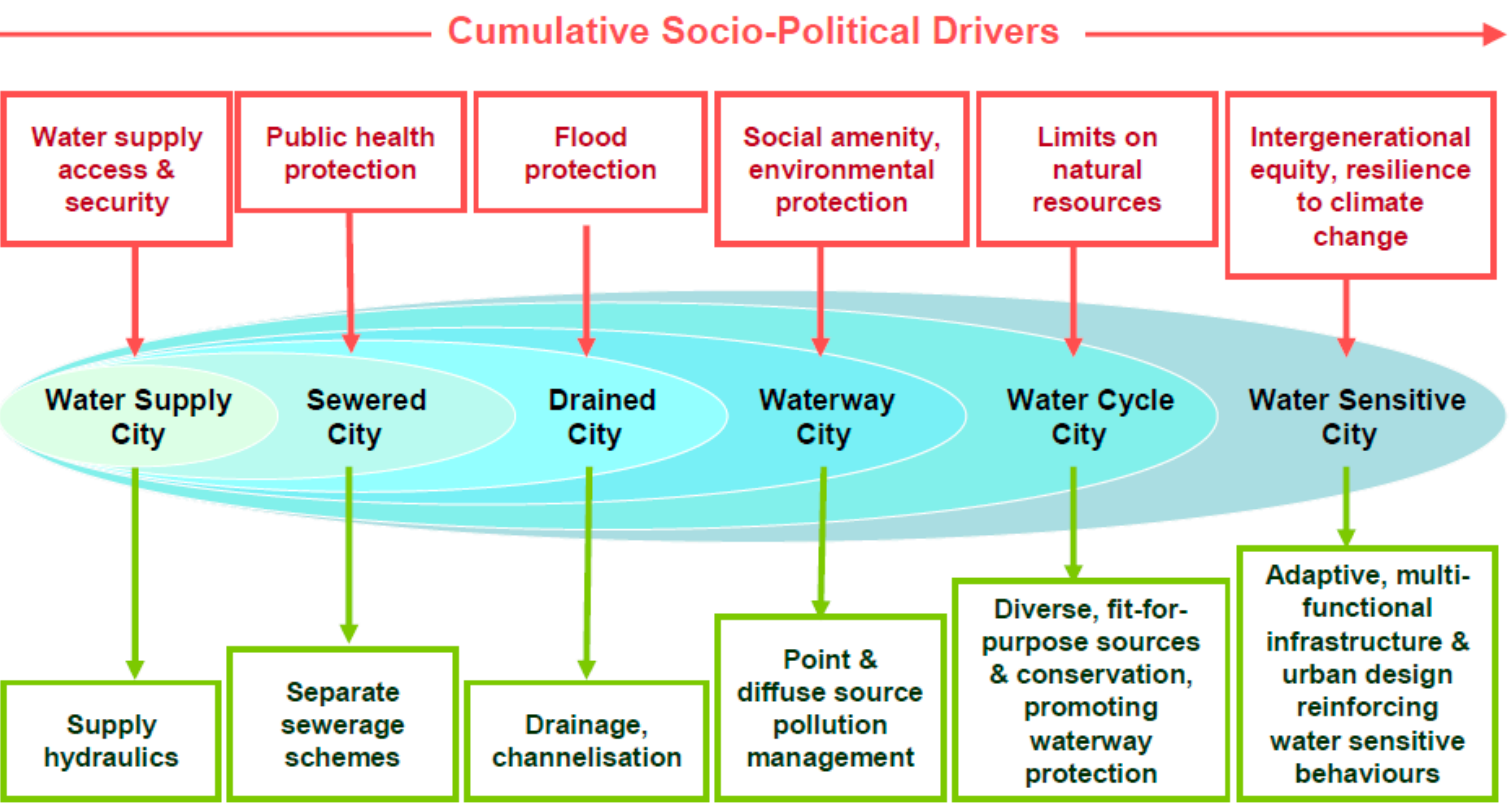

Service Delivery Functions

\subsection{Socio-political system toward water sensitive communities}

While discussing institutional support as the first step to having a decisive effect on promoting water sensitive cities, the social, behavioural patterns and support seems barely incorporated into the overall picture toward Water Sensitive City. To leverage implication of water sensitive behaviour and improve the sustainable living environment, both governance and community initiatives are equally important in the long-term vision. The principles of socio-political system are discussed below to give an insight of social awareness and innovative governance as critical triggers of adapting water sensitive behaviour and decision-making to improve public health and living environment;

- Increase awareness of sustainable lifestyle by drawing water sensitive behaviour into daily life by accepting and using micro-scale storm water systems within the community. For example, neighbourhood or precint level of decentralised storm water system comprises of eco-pond, irrigation system, rainwater catchment in rooftop, podium and ground level which help to harvest storm water and purify before discharging to the central catchment. It benefits the socio-spatial and economic dimensions and helps to mitigate impact of microclimate change; 
- Strengthen government-driven policies in different dimensions by i) conducting a campaign and introducing incentives, subsidy and tax exemption systems as an institutional support to encourage the developers and the community to adopt a sustainable socio-technical system and its long-term vision and benefits; ii) reinforcing urban water management criteria, urban design guidelines, and design checklist to control waterway and urban design. As such, it induces the community development into more sustainable direction in relation to water resources by retrofiting urban water management systems and diversifing water resources with technical support;

- Establish platform for transdisciplinary government agencies; i) to communicate and share the relevant information to avoid overlapping water infrastructure components and optimise the land ; ii) synergise the strength of the various expertise to support water sensitive decision-making in the urban community;

- Promote water sensitive urban design through institutional support that creates decentralised water management system in end-user-oriented perspective. This can help to; i) establish water sensitive behaviour and lifestyle; ii) provide socio-benefits to live in proximity to green and blue environment; iii) diversify water portfolio to enable use of the storm water and recycled waste water in operation and maintenance aspects. In this sense, the private-public partnership (e.g. between government agencies and private developer or consultancy) is necessary to increase understanding regarding sustainable urban water management and the use in the community as micro-scale which connects to the macro scale, centralised system.

The transition of awareness in regard to sustainability toward water sensitive city for both public and private parties is essential for creating the advanced water sensitive society and long-term evolutionary resilience. This transition requires time and institutional support to be embedded in the sustainable urban lifestyle and urban water management system.

\section{2. integrated hydro-technical systems comprising centralised and decentralised models}

Upcoming challenges such as climate change, water scarcity, land use change, population growth, flooding can be unpredictable because of uncertainties. Larsen (2011) stated that one of the solutions is to make centralized water infrastructure more flexible and adaptable. In addition, waste water and storm water are gradually regarded as a valuable resource as these water streams are increasingly being reused and treated (Domènech and Saurí, 2010; Makropoulos and Butler, 2010). In relation to water sensitive city, one of the objectives is to preserve the natural water cycle in the urbanised area. To achieve this in a holistic apporach, an integrated water cycle management is required which includes water sensitive urban design (Hardy et al., 2005).

Integrated socio-technical system comprises of centralized and decentralized models to underpin the diversity of accessible urban water sources to mitigate vulnerability from climate change and optimisation of the land from population growth. Based on the overhaul of existing water infrastructure and trend over past few decades in Singapore, for example, the water management systems shows several challenges as follows: 
- The trend of maximum hourly rainfall increases at an average rate of $6.4 \mathrm{~mm}$ per decade, from an average of $96 \mathrm{~mm}$ in 1980 to $117 \mathrm{~mm}$ in 2012 (public utility board, 2014); and

- developed areas consist largely of paved surfaces. During a storm, more runoff is generated from a developed area.

These trends and conditions have a severe impact on urban built envrionment and adjacent natural environment by causing stress and presure to the existing drainage system and waterway as it is discharged without appropriate treatment or buffer to decrease runoff speed. Thus, a localised water management (drainage and treatment) system is required. As such, establishing decentralized water system is essential in order to;

- synergise with centralised water system to leverage the benefits to the end users in socio-economic, environmental and spatial aspects;

- enhance urban hydro-socio-technical system resilience;

- enable implementation of water management system in the precinct level to control surface runoff water to prevent flooding and water pollution and mitigate the impact of micro-climate change.

The integration of decentralised water system with centralised system has challenges and opportunities. The discussion focuses on selected issues namely:

- the investment (initial cost) and operational cost in the short-terms are relatively higher than the centralised water system currently in place. However it may be cost effective in the long-term urban resilience in relation to water reuse and access to diverse water resource;

- how does decentralised system consititute to cohesive network is a practical challenge, it requires to consider contextual background of current water infrastructure based on the present policy.

From an environmental perspective, water reuse can reduce demand for fresh water resources, diversify water portfolio and enhance security of access to the resources; it can reduce the volume of wastewater dischardged into the environment. Decentralised system can reduce energy required to transport water from the point of protection to the point of use; and reduce greenhouse gas emissions (OECD, 2009)

\subsection{Environmental Resilience in built and natural environment}

The stress of climate change and population growth results in flooding, water pollution, additional investment on securing water resources and maintenance of water infrastructure. The water pollution from the runoff is particularly critical issue regarding the impact to the natural environment in the city; in some cases, such stress is beyond the capability of self-purification of the environment. Also traditional knowledge 'value' of open space and landscape features in the urban envrionment needs to be bolstered with an understanding of the 'ecological functioning' of the urban landscape that capture the essences of sustainable water management, micro-climate influences, facilitation of carbon sinks and use for food production (Wong and Brown, 2009).

The environmental resilience in built and natural environment requires both socio-technical support and protection, it aims to enhance the quality of waterway, and public health as a part of green 
infrastructure such as bioretention system and wetland; it protects diverse water resources and gives direct influence on urban livign enviornment. As discussed from the chapter 2.2. integrated hydrotechnical systems comprising centralised and decentralised models can support technical aspects of the water management and green infrastructure. Built environment in particular requires water sensitive urban design for holistic approach to ensure resilience in relations to socio-technical system and natural environment by creating spatial and technical solutions in various level from the building, open space to the regional park.

In the past, we often discussed environment resilience in the public realm while the private realm does not have enough room to accommodate considerable and sustainable design approach related to water management and water reuse to create socio-economic and environmental benefits in particular. The private realm has several constraints like limited financial support, duration of design and construction and additional operational and maintenance cost in the short-term. In addition, there are not many cases yet implemented.

In relation to the paradigm shift from the public realm oriented water management system to integrated system of both public and private realms, it requires interdisciplinary collaboration among different sectors especially urban designer, architect and landscape designer. In addition, the government's institutional support is still the key driver in this aspect.

\subsection{Water sensitive development in Singapore}

Singapore was planned as garden city in 1960's with provision of proximity of green to living environment. It has $8,000 \mathrm{~km}$ of waterways and 17 reservoirs for the water supply. In recent years, government initiated several approaches towards sustainability, in particular water management due to the scarcity of the water, desalination, population growth, climate change and so forth. The discussion focuses more on several issues as follows:

- Singapore is building diversity of reuseable water resources through NEWater recycled wate water scheme, a desalination plant, water catchment area by reclamation and reservoir and so on;

- For the long-term vision, Deep Tunnel Sewerage System (DTSS) was conceived in the 1990s for collection of Singapore's used water, treatment, reclamation and disposal needs. It is centralised system which comprises a network of linked sewers leading to two major tunnels criss-crossing Singapore with three large Water Reclamation Plants (WRP) at three areas - Kranji, Changi and Tuas - as well as deep sea outfall pipes. It is a more cost effective solution than renewing and expanding the legacy of used water infrastructure to free up land for other development in Singapore. However, there is still a demand to minimise direct impact on the neighbourhood scale. Therefore, decentralised water infrastructure requires socio-technical support on the neighbourhood scale to integrate with centralised water infrasturcture;

- In terms of social and spatial dimensions, Singapore initiated Active Beautiful Clean (ABC) Water guidelines in 2009 which focuses more on public realm regarding how to implement environmentally sustainable green features in the development. Now, it is more intensified by shared common vision of sustainable water management through the guidelines and certification 
system in conjunction with strenthened institutional framework and increasing awareness of collaboration among different parties.;

- The water sensitive development initiative has been initiated in the WSUD pilot project of Kallang Riverside Masterplan in proximity to the last historical coastal line of Singapore.

\section{Anticipated challenges}

During the transition toward more sustainable water sensitive city, there are several anticipated challenges discussed in this chapter as follows:

- Interdisciplinary government structure: it is known to be difficult to collaborate due to the sensitivity of the contents, ownership of data, integrated data system for ease of use, and current policy. Therefore it is required to check the current status of urban water system, institutionalisation level and patterns of hydro spatial usages in private and public realms to plan the integrative governmental framework which fits the local and regional government contexts of development direction, plan and concern;

- Integration of spatial scale and built form is a practical challenge, as various parties need to be involved and collaborate such as architect, landscape architect, urban designer, and so forth. In addition, WSUD guidelines need to be established for ensuring the spatial quality and environment resilience, which in turn influences urban living quality as well as environment sustainability.

\section{Conclusions}

The urban society is beginning to realise the significance of the climate change and global warming as these impacts and challenges are gradually increasing to the new urban community as well as the urban community recognise and strive to seek for a solution toward resilience to counter future uncertainties and challenges for liveability. Therefore, it requires a significant paradigm shift in urban design.

The pursuit of urban resilience requires understanding its complexity, approach from the various dimensions and overhaul of the current situation. The sustainability of the city is changing based on the needs of the times and environment and influence from the significant impact of climate change. Thus, water sensitive urban design needs to be drawn into the sustainable lifestyle of the community. To design and plan liveable and environmentally responsible communities in particular entails a holistic approach to each community design element that affects the ecological footprint of urban environment. This approach can mitigate carbon footprint of the urban development, enhance biodiversity and protect environment and water resources. The water sensitive city, in particular, is one of the fundamental components to approach establishment of a sustainable community. Especially it is applicable to Singapore which has relatively bigger impacts from the climate change regarding water resource in relation to flooding, drought, increasing annual rainfall including a local downpour, potable water, desalination, wastewater management, sewage disposal and storm water management. To create a water sensitive city, the transdisciplinary approach is an essential process to contextualise global sustainable principle to increase local opportunities and cope with constraints from socio-economic and spatial aspects. 
The key principles of water sensitive city in various dimensions are established. Firstly, the institutional context is a core driver of creating the water sensitive city, while the sustainable social behaviour stimulates adaptation of the water sensitive behaviour and lifestyle in the community as a catalyst to support in the aspects of socio-political system. In addition, the socio-technical system is to relieve the influence of the climate change and global warming, by adapting decentralised water management system, in which the spatial design of private public realms in the precinct, district scales is integrated. It links with a centralised system to synergise urban water management in a holistic manner. Thereby achieving environment resilience. A contextualised socio-technical model and institutional support are required to implement a water sensitive city.

\section{References and Notes}

1. Dominguez, Truffer, and Gujer, Tackling uncertainties in infrastructure sectors through strategic planning: the contribution of discursive approaches in the urban water sector. . Water Policy, 2011. 13(03): p. 299-316.

2. Pahl-Wostl, C., Transitions towards adaptive management of water facing climate and global change. Water Resour Manage, 2007. 21: p. 49-62.

3. Bernhard Truffer, E.S., Max Maurer and Annette Ruef, Local Strategic Planning Processes and Sustainability Transitions in Infrastructure Sectors. Environmental Policy and Governance, 2010. 20: p. 258-269.

4. Briony C Ferguson, N.F., Rebekah R Brown, A strategic program for transitioning to a water sensitive city. Landscape and Urban Planning, 2013. 117: p. 32-45.

5. Butler and Maksimovic, Urban water management-challanges for the third millennium. Environmental Science, 1999. 1: p. 213-236.

6. Newman, P., Sustainable urban water systems in rich and poor cities - steps towards a new approach, Water Science \& Technology, 2001. 43: p. 93-99.

7. Ashley, R., et al., Sustainable decision making for the UK water industry. Proceedings of the ICE Engineering Sustainability, 2003. 156(ESI): p. 41-49.

8. Dalziell, E.P. and S.T. McManus, Resilience, Vulnerability, and Adaptive Capacity: Implications for System Performance, 2004, Switzerland: International Forum for Engineering Decision Making (IFED).

9. Porter, S.D.a.L., 'Resilience: A bridging concept or a dead end?' Planning Theory \& Practice, 2012. 13(2): p. 299-307.

10. Holling, C.S., Resilience and stability of ecological systems. Annual Review of Ecology and Systematics, 1973. 4: p. 1-23.

11. Folke, C., Resilience: The emergence of a perspective for social-ecological systems analyses. Glob. Environ. Change, 2006. 16(3): p. 253-267.

12. Wilkinson, C., Urban resilience: what does it mean in planning practice? Planning Theory \& Practice, 2012. 13(2): p. 319-324.

13. Béné, C., Godfrey Wood, R., Newsham, A. \& Davies, M., Resilience: New utopia or new tyranny? Reflection about the potentials and limits of the concept of resilience in relation to vulnerability reduction programmes. 2012, Brighton: IDS. 
14. Levine, S., Pain, A., Bailey, S. \& Fan, L., The relevance of 'resilience'? 2012, London: ODI.

15. ARUP, Research Report Volume 1 Desk Study, in City Resilience Index. 2014, ARUP: London.

16. da Silva, et al., A systems approach to meeting the challenges of urban climate change. International Journal of Urban Sustainable Development 2012. 4(2): p. 125-145.

17. Wong, T.H.F., Chapter 1 Introduction, in Australian Runoff Quality: A Guide to Water Sensitive Urban Design, T.H.F. Wong, Editor. 2006a, Engineers Australia: Canberra.

18. Wong, T.H.F., Water sensitive urban design - the journey thus far. Australian Journal of Water Resources 2006b. 10(3): p. 213-221.

19. Mitchell, V.G., Applying Integrated Urban Water Management Concepts: A Review of Australian Experience. Journal of Environmental Management 2006. 37(5): p. 598-605.

20. Brown, R.R.a.C., J Transition to Water Sensitive Urban Design: The story of Melbourne. 2007.

21. Brown, R., N. Keath, and T. Wong, Urban water management in cities: historical, current and future Regimes. Water Science and Technology, 2009. 59(5): p. 847-855.

22. A., L.T., Redesigning wastewater infrastructure to improve resource efficiency. Water Science and Technology, 2011. 63(11): p. 2535-2541.

23. J., H.M., K. G., and C.P. J., Integrated urban water cycle management: the UrbanCycle model. Water Science and Technology, 2005. 52(9): p. 1-9.

24. Board, P.U., Managing stormwater for our future. 2014, Pulbic Utility Board: Singapore.

(C) 2015 by the authors; licensee MDPI and IFoU, This article, is an open-access article distributed under the terms and conditions of the Creative Commons Attribution license. 